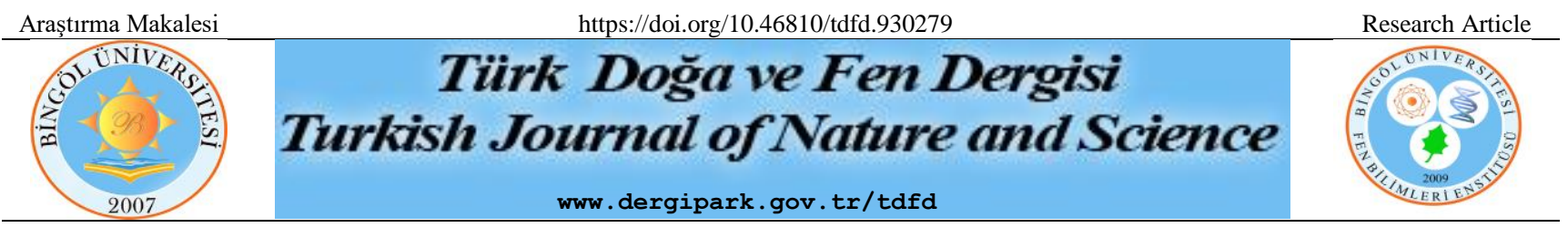

\title{
Stiren-Bütadien Kauçuk Lateks Modifiyeli Harçların Erken Yaştaki Fiziksel ve Mekanik Özelliklerinin İncelenmesi
}

\author{
Kasım MERMERDAŞ ${ }^{1}{ }^{*}, Z_{\text {Zeynep ALGIN }}{ }^{1}$, Şevin EKMEN ${ }^{1}$, Metin KARADAĞ ${ }^{\mathbf{1}}$ \\ ${ }^{1}$ Harran Üniversitesi, Mühendislik Fakültesi, İnşaat Mühendisliği Bölümü, Şanlıurfa, Türkiye \\ Kasım MERMERDAS ORCID No: 0000-0002-1274-6016 \\ Zeynep ALGIN ORCID No: 0000-0001-7004-8403 \\ Şevin EKMEN ORCID No: 0000-0002-2577-696X \\ Metin KARADAĞ ORCID No: 0000-0002-1883-1078 \\ *Sorumlu yazar: kasim.mermerdas@harran.edu.tr
}

(Alınış: 30.04.2021, Kabul: 29.09.2021, Online Yayınlanma: 31.12.2021)

\begin{abstract}
Anahtar
Kelimeler

İşlenebilirlik,

Harç,

Mekanik

özellikler,

Stiren-

Bütadiyen

Kauçuk

lateks,

Öz: Portland çimentosu, harç ve beton yapımında yaygın olarak kullanılmaktadır. Ancak çimento harc1 ve betonun gecikmiş priz süresi, düşük çekme dayanımı, yüksek kuruma büzülmesi ve düşük kimyasal direnç gibi bazı dezavantajları vardır. Polimerler bu dezavantajları ortadan kaldırmanın yanı sıra, betonun işlenebilirliğini ve geçirimsizliğini arttırmak amacıyla katkı maddesi olarak kullanılabilmektedirler. Bu çalışmada, Stiren-Bütadien Kauçuk lateksinin kütlece farklı ikame oranlarını $(\% 0, \% 5, \% 10, \% 15$ ve $\% 20)$ içeren harçların erken yaştaki (14 gün) sertleştirilmiş özellikleri incelenmiştir. Taze harç için yayılma ve birim ağırlık ölçümleri yapılırken, sertleşmiş harç üzerinde birim ağırlık, basınç dayanımı, eğilme dayanımı, su emme ve kapiler su emme testleri yapılmıştır. Sonuç olarak harç karışımlarında lateks miktarı arttıkça dayanım değerlerinin azaldığı görülmüştür. Lateks kullanımına bağlı olarak eğilme dayanım değerlerinde düşüş gözlenirken, \%10 oranında lateks kullanımı kontrol karışımına kıyasla numunelerin eğilme dayanımı değerlerinde \%3 oranında küçük bir artış sağlamıştır. Taze ve sertleşmiş harç numunelerinin birim ağırlıkları kontrol numunesine göre artmıştır. Kullanılan lateks, harçların işlenebilirliği, su emme ve kılcal su emme değerleri üzerinde olumlu bir etkiye sahip olmuştur.
\end{abstract}

\section{Investigation of Physical and Mechanical Properties of Styrene-Butadiene Rubber Latex Modified Mortars at Early Age}

Keywords Workability, Mortar, Mechanical properties, StyreneButadiene Rubber latex

\begin{abstract}
Portland cement has been widely used in mortar and concrete construction. However, there are some disadvantages such as, delayed setting time of cement mortar and concrete, low tensile strength, high drying shrinkage, and low chemical resistance. In addition to eliminating these disadvantages, polymers can be used as concrete admixtures to enhance the workability and impermeability of concrete. In this study, fresh and hardened properties of mortars containing different replacement ratios of Styrene-Butadiene Rubber latex by mass $(0 \%, 5 \%, 10 \%, 15 \%$, and $20 \%$ ) at early age (14 days) were examined. The flow and fresh unit weight measurements were made for fresh mortar, while compressive strength, flexural strength, unit weight, water absorption, and capillary water absorption tests were conducted for hardened mortar. As a result, it was observed that the strength decreases as the amount of latex increases in the mortar mixes While a decrease was observed in the flexural strength values due to the use of latex, the use of $10 \%$ latex resulted in a small increase of $3 \%$ in the flexural strength values of the samples compared to the control mixture. The unit weights of the fresh and hardened mortar samples increased compared to the control sample. The latex addition used has a positive effect on workability, water absorption, and sorptivity of the mortars.
\end{abstract}




\section{GíRIŞ}

Geleneksel yöntemlerle üretilen yap1 sistemleri, basınç dayanımı, istenilen şekli verebilme, hammaddenin hazır bulunabilirliği ve düşük maliyeti gibi nedenlerle inşaat sektöründe tercih edilmektedir. Bazı yapılar ciddi kimyasal saldırıya, artan gerilme seviyelerine ve darbe yüklerine maruz kalmaktadır. Ek olarak, beton yapıların onarımında sıradan bir çimento sisteminin kullanımı, nispeten düşük çekme dayanımı ve darbe dayanımı, agresif etkenlerin girişine zayıf direnç ve eski betona zayıf yapışması nedeniyle sınırlıdır [1]. Bu nedenle, bir yap1 malzemesinin çok yönlülüğünü ve esnekliğini değiştirmeden çimento sisteminin özelliklerini değiştiren malzemeler bulmak giderek daha çekici hale gelmektedir [2]. Bilim ve teknolojide araştırma ve geliştirmenin ortaya çıkması sonucu, beton endüstrisi de çeşitli beton yeniliklerinin tanıtılmasıyla gelişmiştir ve bu nedenle belirli talep ve özelliklere uygun ve farklı beklentileri karşılamak üzere özel betonlar üretilmektedir. 1950'lerde Portland çimento harcı ve betonda polivinil asetat ve poliakrilat olarak sentetik polimerler kullanılmıştır. Düzinelerce monomer türünün değiştiricilerle farklı kombinasyonları, inşaat endüstrisinde yaygın olarak kullanılan çeşitli lateks türlerini üretmektedir [3]. Bu polimer lateksler arasında Portland çimento harçlarının fiziko-mekanik özelliklerini ve dayanıklılığını iyileştirmek için en yaygın kullanılan lateks türleri SBR (Stiren-Bütadien Kauçuk), SAE (Stiren Akrilik Ester), EVA (Etilen Vinil Asetat, PAE (Poliakrilik Ester) ve SAR (Stiren Akrilat Kauçuk)'tur [4-6]. Kullanılan latekslerin harç/betondaki etki mekanizması 3 aşamada gerçekleşmektedir. Karışıma eklenen lateks faz içerisinde ilk olarak homojen bir şekilde dağılır. Daha sonra polimer yap1 çimento jeli ve çimento daneleri üzerinde birikmeye başlar ve son olarak kapiler boşluklarda hapsolan polimerler hidratasyon reaksiyonları sonrasında bünyedeki suyun da ortamı terk etmesi ile film tabakalarını oluşturur ve agrega yüzeyini kaplar. Böylece bütün bir ağ yapısı oluşmuş olur ve bu monolitik yapı sayesinde üretilen yapı malzemesi daha sünek ve geçirimsiz bir özellik kazanır. Lateksin harçlardaki etkisinin derecesi, lateksin türüne ve karışımdaki konsantrasyonuna büyük ölçüde bağlıdır [78]. Çimento teknolojisinde Stiren-Bütadien Kauçuk (SBR) lateksi olarak kullanılan sentetik polimerler birçok cephede tanınmıştır [9-11]. Öte yandan, polimer modifiyeli harçların mükemmel performansları nedeniyle, özellikle bitirme ve onarım işlerinde [12-13] popüler yapı malzemeleri olarak kullanıldığına dikkat edilmelidir. Kullanılan polimerlerin türü, katı içeriği, PH değeri, yoğunluk ve minimum oluşum sıcaklığı gibi tipik özelliklerine bağlı olarak üretilen bu yap1 malzemelerinin sıradan çimento harçlarını etkileyebilecek aynı parametrelerden etkilendiklerini söylemek mümkündür [7]. Yap1 malzemelerinin işlenebilirlik, eğilme dayanımı ve durabilite özellikleri polimerlerin kullanımından büyük ölçüde etkilenmektedir [14-15]. Beton teknolojisinde şüphesiz ki stiren-bütadien polimerleri, kural olarak en çok kullanılan polimer malzemelerdir [16]. SBR, çeşitli malzemelerle başarılı bir şekilde birleştirilebilen, bütadien, stiren ve su içeren geniş dağılımlı bir polimerdir [17-18]. İnşaat mühendisliği alanında SBR, betonun sertleşmiş özelliklerini artırmak için çimentonun bir ilavesi olarak kullanılmaktadır [19]. Araştırma sonucunda SBR ilavesinin betonun dayanım özelliklerine etkisi olduğu görülmüştür. Elde edilen polimer film ve çimento hidratı sonucunda yüksek adezyon gözlenmektedir. Siradan betonla karşılaştırıldığında, bu etki daha az deformasyona neden olarak betonun ezilme ve eğilme dayanımını iyileştirmektedir [20]. SBR lateksi, modifiye solüsyonlarda büyük ölçüde yaygın bir kullanıma sahiptir. Bulgular, SBR ile modifiye edilen çözümlerin gelişmiş mekanik parametrelere, yani gelişmiş sızdırmazlığa ve donma etkisine karşı daha fazla dirence sahip olduğunu göstermiştir. SBR lateks içeren beton üzerinde birçok araştırma yapılmıştır [21-23]. Aşağıdaki paragrafta, SBR'nin çimentolu kompozitlerde kullanımına ilişkin bir literatür taraması sunulmaktadır.

Ohama ve ark. [24] stiren-bütadien kauçuk (SBR), poliakrilik ester (PAE) ve polivinil asetat (PVAC) gibi latekslerin harç ve betona katıldığında işlenebilirliğe nasıl bir etki ettiği üzerine yaptıkları çalışmada, lateksin harç ve betonda işlenebilirliği arttırdığını bulmuşlardır. Rossignolo [25] silis dumanı ve SBR lateksin arayüzey geçiş bölgesi (ITZ) ve mikro yapı üzerindeki etkisinin araştırılmasında, silis dumanı ve SBR lateks katkılı harçların kontrol numunelerine göre daha iyi sonuçlar verdiğini belirtmiştir. Benali ve Ghomari [26] SBR lateks modifiyeli harçlar üzerinde akışkanlık, basınç dayanım, eğilme dayanımı, su emme testleri ve yapışma testleri üzerine yapılan çalışmalarında, 60 gün ve daha ileriki günler için eğilme dayanımında bir gelişme kaydedildiğini, tüm süreler için basınç dayanımının azaldığını, su emme yüzdesinde de belirgin bir azalma olduğunu gözlemlemişlerdir. Idrees ve Nazar [27] SBR lateksin infüzyonunun harç üzerine etkisinin araştırılmasında, numunelerin yarmada çekme dayanımının \%34, eğilme dayanımının 3 kat ve tokluğun 4 kat oranında arttığını belirtmişlerdir. Rossignolo ve Agnessini [28] SBR lateks katkılı hafif beton üzerinde kimyasal dayanıklılık, korozyona dayanıklılık, su emme deneyleri ve kuru birim hacim ağırlık deneylerini gerçekleştirmişlerdir. Çalışmanın sonucunda kuru birim hacim ağırlığın 1460-1605 kg/m ${ }^{3}$ olduğunu, su emme ve kimyasal dayanıklılığın katkısız olanlara göre daha iyi sonuçlar verdiğini göstermişlerdir. Shafieyzade [29] SBR ve silis dumanı katılarak elde edilen betonların basınç dayanımının incelendiği çalışmada, lateks ilavesinin artışıyla basınç dayanımının azaldığını belirtmiştir. Essa ve ark. [30] SBR lateks katkısının eski ve yeni beton üzerindeki etkisi ile ilgili çalışmalarında, çimento harçlarının su miktarını hacimce $\% 10, \% 25$ ve $\% 35$ oranlarında SBR ile değiştirerek 7., 28. ve 60. günlerde basınç ve eğilme dayanımı değerlerini araştırmışlardır. Çalışma sonucunda SBR katkısı ile hazırlanan harç numunelerinde kür süresi ile dayanım arasında doğru bir ilişkinin varlığını belirtmişlerdir. Soni ve Joshi [31] tarafindan, SBR lateksin betonun basınç ve eğilme dayanımı üzerindeki etkisi çalışılmış ve beton için optimum lateks içeriği hesaplanmıştır. Bunun için beton karışımlarına $\% 0, \% 5, \% 10, \% 15$ ve $\% 20$ 'lik SBR lateks katılarak farklı yaşlar için basınç dayanımı ve 
eğilme dayanımları hesaplanmıştır. Çalışmanın sonucunda lateks ilavesinin erken yaşlarda basınç ve eğilme dayanımlarında düşüşe neden olduğu, 28. günde ise artışa neden olduğu gözlemlenmiştir. Bideci ve ark. [32], çimento harçlarına ağırlıkça \%0 (Kontrol), \%5, $\% 10, \% 15$ ve $\% 40$ oranlarında SBR ilavesi katılarak elde edilmiş deney numunelerinin fiziksel, kimyasal ve mekanik özellikleri incelemiştir. Ayrıca, numunelerin SEM/EDS analizleri yapılmıştır. Çalışmanın sonucunda, \%5 Stiren Bütadien kopolimer katkısının çimento harçlarının basınç dayanımına olumlu etkisi olduğu görülmüştür. Shirshova vd. [33] çimento kütlesine göre $\% 14$ SBR içeren çimento bulamacını değerlendirmişlerdir. SBR polimer lateks kullanımı nedeniyle sürekli bir polimer ağı oluştuğunu ve bu durumun çimento hamurunun basınç dayanımı üzerinde olumsuz etki gösterirken gerilme-göçme oranını arttırdığını bildirmişlerdir. Schulze [34], polimer içeren harçların özelliklerine ilişkin su/çimento oranının ve çimento içeriğinin etkisini incelemiştir ve SBR içeriğinin $\% 20$ 'ye varan artışı ile SBR içeren harcın eğilme dayanımının arttığını ve ardından dalgalanma gösterdiğini bildirmişlerdir. $\mathrm{Wu}$ vd. [35] SBR kullanılarak harcın su geçirmezlik özelliğinin büyük ölçüde artırıldığını bildirmişlerdir. Issa vd. [36] SBR polimer modifiyeli betonun kaplama betonunun tokluğunu artırabileceğini bildirmişlerdir. Shaukat vd. [37] elyaf takviyesinin polimer modifiyeli beton üzerindeki etkisini incelemiş ve harç içerisine polimer ilavesinin çimento ve agrega ile birlikte daha iyi polimer film geliştirdiğini ve geleneksel harca kıyasla etkili sonuçlar gösterdiğini bildirmiştir. Singh vd. [38] işlenebilirlik, eğilme dayanımı ve çekme dayanımı gibi mekanik performansların; polimer içeriği artırılarak iyileştirilebileceğini belirtmişlerdir. Tchetgnia vd. [39] farklı çevre koşullarında polimer modifiyeli harcın geleneksel çimento harcı ile karşılaştırıldığında etkili dayanım ve dayanıklılık özellikleri ortaya çıkardığını açıklamışlardır. Wang vd. [40] polimer lateks modifiye çimentonun mekanizmasını araştırmış ve aktif grupları olmayan polimer lateksin benzer fiziksel modifikasyon mekanizması gösterdiği sonucuna varmıştır.

Literatür çalışmalarında bazı lateks malzemeler kullanılarak üretilen harçların taze özellikleri, mekanik ve durabilite özellikleri genellikle ileriki yaşlar için incelenmiştir. Deneysel çalışmamızda, farklı bir SBR lateks (Mastercast-125) değişen yüzdelerde kullanılarak erken yaşta taze ve sertleşmiş harçların üzerindeki etkileri incelenmiş ve en iyi performansı veren katk1 oranının belirlenmesi amaçlanmıştır. Kullanılan SBR lateks oranları çimentonun kütlece $\% 0$ (Kontrol), $\% 5$, $\% 10, \% 15$ ve $\% 20$ 'si olarak belirlenmiştir. SBR lateks akışkanlığı etkilediği için $20 \pm 5 \mathrm{~cm}$ aralığında akış değerleri elde etmek için akışkanlaştırıcı miktarında düzenleme yapılmıştır. Lateks katkılı karışımlarda taze harç için yayılma ve birim hacim ağırlık ölçümleri yapılırken sertleşmiş harç için birim ağırlık, basınç dayanımı, eğilme dayanımı, su emme ve kılcallık deneyleri yapılmıştır. Böylece SBR lateks kullanımının harçlar üzerindeki etkisi irdelenmiştir.

\section{MATERYAL VE METOT}

Yürütülen çalışmada kullanılan malzemeler; kum, çimento, SBR lateks ve akışkanlaştırıcıdır. Üretilen tüm karışımlarda $4 \mathrm{~mm}$ açıklığa sahip elekten elenmiş dere kumu kullanılmıștır. Kullanılan kumun özgül ağırlığı 2,65 su emme değeri ise 1,4 olarak belirlenmiştir. 2,59 incelik modülüne sahip kumun bünyesinde bulunan kimyasal oksitler Tablo 1.'de verilmiștir.

Tablo 1. Dere kumunun kimyasal bileşenleri

\begin{tabular}{|l|l|}
\hline Oksit $(\%)$ & Dere kumu \\
\hline $\mathrm{SiO} 2$ & 96,39 \\
\hline $\mathrm{Al} 2 \mathrm{O} 3$ & 1,69 \\
\hline $\mathrm{Fe} 2 \mathrm{O} 3$ & 0,21 \\
\hline $\mathrm{CaO}$ & 0,15 \\
\hline $\mathrm{MgO}$ & 0,25 \\
\hline $\mathrm{Na} 2 \mathrm{O}$ & 0,05 \\
\hline $\mathrm{K} 2 \mathrm{O}$ & 0,23 \\
\hline $\mathrm{TiO} 2$ & 1,03 \\
\hline
\end{tabular}

Kullanılan dere kumuna ait elek analiz grafiği alt ve üst sınır grafikleri ile birlikte Șekil 1.'de sunulmuștur.

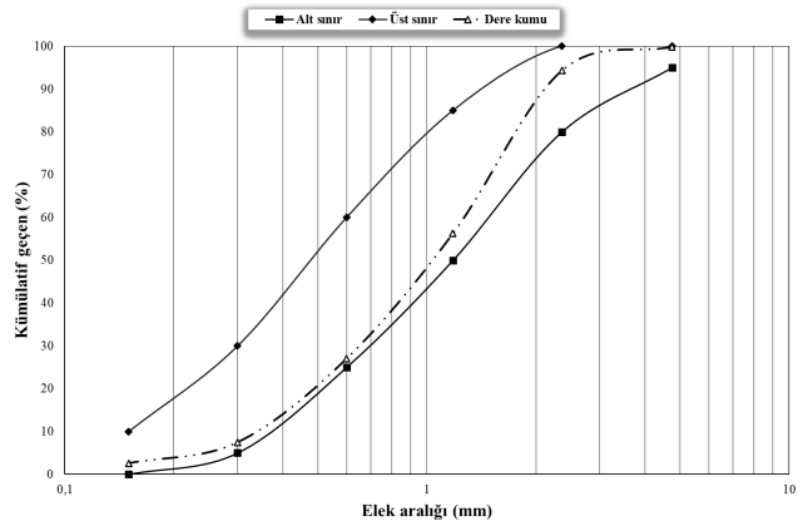

Şekil 1. Dere kumuna ait elek analiz grafiğ

Deneysel çalışmada, Kahramanmaraş çimento fabrikasında üretilen (KÇS) CEM I 42,5N tipi çimento kullanılmıştır. Kullanılan çimentonun özgül ağırlığ 3,15 tir. Tablo 2.'de çimentonun kimyasal ve fiziksel özelikleri görülmektedir.

Tablo 2. CEM I 42.5N çimentonun kimyasal ve fiziksel özellikleri

\begin{tabular}{|l|r|l|r|}
\hline \multicolumn{2}{|c|}{ Kimyasal bileșenler } & 62,8 & \multicolumn{2}{c|}{ Priz başlangııs (dakika) } & 200 \\
\hline $\mathrm{CaO}$ & 20,05 & Priz sonu (dakika) & 240 \\
\hline $\mathrm{SiO}_{3}$ & 4,9 & Özgül Ağırlık & 3,15 \\
\hline $\mathrm{Al}_{2} \mathrm{O}_{3}$ & 3,7 & Hacim genişlemesi & 1,3 \\
\hline $\mathrm{Fe}_{2} \mathrm{O}_{3}$ & 2,48 & $\begin{array}{l}\text { Özgül yüzey (Blaine) }\left(\mathrm{cm}^{2}\right. \\
\text { /g) }\end{array}$ & 3880 \\
\hline $\mathrm{SO}_{3}(\%)$ & 0,85 & Litre ağırlı̆̆ı $\left(\mathrm{g} \mathrm{l}^{-1}\right)$ & 950 \\
\hline $\mathrm{MgO}(\%)$ & 2 & 2 günlük dayanım(MPa) & 28,1 \\
\hline $\mathrm{Kızdırma} \mathrm{Kaybı} \mathrm{( \% )}$ & 0,4 & 28 günlük dayanım(MPa) & 54,5 \\
\hline $\begin{array}{l}\text { Cözünmeyen Kalınt1 } \\
(\%)\end{array}$ & & & \\
\hline
\end{tabular}

Hazırlanan tüm karışımlarda SBR lateks olarak BASF firmasına ait Mastercast-125 ürünü kullanılmıştır. Şekil 2.'de kullanılan SBR lateksin görüntüsüne Tablo 3.'te ise ürüne ait özelikler görülmektedir. 


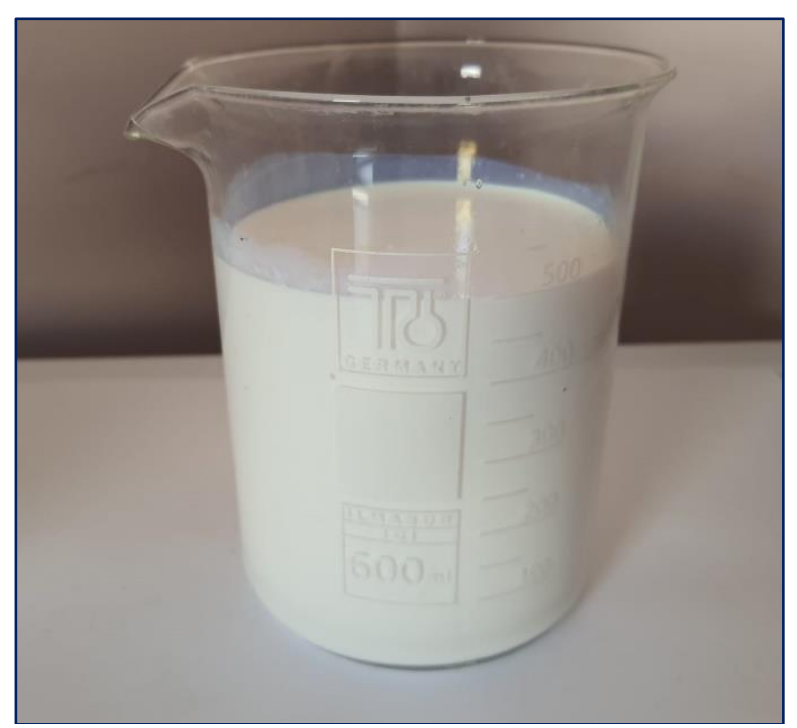

Şekil 2.. SBR lateks ürününe ait görüntü

Tablo 3. SBR lateks ürününün özellikleri

\begin{tabular}{|l|l|}
\hline Malzemenin Yapısı & Modifiye edilmiş akrilik dispersiyon \\
\hline Görünüm & Beyaz \\
\hline Özgül ağırlık $\left(\mathbf{2 0}^{\circ} \mathbf{C}^{\prime} \mathbf{d e}\right)$ & 1,08 \\
\hline pH-değeri & $7-9$ \\
\hline Uygulanacak Zemin Sıcaklığı & $+5^{\circ} \mathrm{C}+35^{\circ} \mathrm{C}$ \\
\hline Servis Sıcaklığı & $-20^{\circ} \mathrm{C}+80^{\circ} \mathrm{C}$ \\
\hline
\end{tabular}

Çalışmada kullanılan süper akışkanlaştırıcı polikarboksilik-eter esaslı olup 1,07 birim ağırlık değerine sahiptir. K1 (kontrol), K2 (\%5 SBR) ve K3 (\%10 SBR) karışımlarında istenen yayılma değerini elde etmek için çimento ağırlığının \%0,25'i ile \%1'i arasında değişen miktarlarda süper akışkanlaştırıcı kullanılmıştır.

Laboratuvar ortamında hazırlanan deney numuneleri için malzeme karışım dizaynı Tablo 4.'te verilmiştir. $\mathrm{Su}$ /çimento oranı 0,4 olarak belirlenmiştir. Kullanılan lateks bünyesinde bulunan $\% 42$ katı malzeme oran1 dikkate alınarak kullanılan çimento miktarı, \%58 oranındaki su miktari dikkate alınarak da karışım suyu miktarı azaltılmıştır. Elde edilen numuneler 24 saat üstü kapatılmış vaziyette kalıplarda bekletilmiş bu süre sonunda kalıptan alınan numuneler erken yaş (14 gün) özelliklerinin belirlenmesi amaciyla standart kür ortamına $\left(20 \pm 2{ }^{\circ} \mathrm{C}\right.$-bağıl nem \%100) bırakılmıştır.

Tablo 4. Malzeme karışım dizaynı $\left(1 \mathrm{~m}^{3}\right)$

\begin{tabular}{|c|c|c|c|c|c|}
\hline $\begin{array}{c}\text { Karışım } \\
\text { kodu }\end{array}$ & $\begin{array}{c}\text { Çimento } \\
(\mathbf{k g})\end{array}$ & $\begin{array}{c}\text { SBR } \\
(\mathbf{k g})\end{array}$ & $\begin{array}{c}\text { Akışkanlaştırıcı } \\
(\mathbf{k g})\end{array}$ & Su(kg) & $\begin{array}{c}\text { Kum } \\
(\mathbf{k g})\end{array}$ \\
\hline $\mathrm{K} 1(\% 0)$ & 542 & & 5,7 & 216 & 1622 \\
\hline $\mathrm{K} 2(\% 5)$ & 507 & 64 & 2,7 & 176 & 1601 \\
\hline K3(\%10) & 474 & 126 & 1,4 & 136 & 1579 \\
\hline K4(\%15) & 441 & 187 & - & 100 & 1555 \\
\hline K5(\%20) & 412 & 242 & - & 52 & 1545 \\
\hline
\end{tabular}

Yayılma Tablası Deneyi, ASTM C 1437 [41] standardına uygun olarak gerçekleştirilmiştir. Harç, kesik koni içine iki tabaka halinde yerleştirilmiş ve her tabaka $25 \mathrm{kez}$ tokmaklanarak sıkıştırılmıştır. Harç kalıptan çıkarıldıktan sonra 15 saniyede $25 \mathrm{kez}$ sarsılarak ortalama yayılma çapları bulunmuştur.

Üretilen taze ve sertleşmiş numunelerin birim ağırlık deneyi ASTM C138 [42] standardına uygun olarak gerçekleştirilmiştir. Her karışım için 3 küp numunesine ait sonuçlarının ortalaması alınmıştır.
Eğilme deneyi, ASTM C348-18 [43] standardına uygun olarak 3 adet 40x40x160 mm boyutlara sahip 14 günlük harç numunelerinin $1 \mathrm{MPa} /$ dak yükleme hızında kırılmaya tabi tutulmasıyla gerçekleştirilmiştir. Basınç dayanımı testi için eğilme dayanımında ikiye bölünmüş olan olan 6 adet numune kullanılarak, test cihazına uygun vaziyette yerleştirilmiş ve $2,4 \mathrm{kN} / \mathrm{s}$ yükleme hızında kırılmıștır.

Su emme deneyi ASTM C642-13 [44] standardına uygun olarak gerçekleştirilmiştir. Su emme deneyinde, 14 günlük 3 adet $5 \times 5 \times 5 \mathrm{~cm}$ boyutunda numune oda sıcaklığında içi su ile dolu bir kap içerisine doygun hale gelinceye kadar bekletilmiştir. Numuneler sudan çıkarılmış ve yüzeylerindeki su bir bez vasıtasıyla alındıktan sonra hassas terazide tartılmıştır (ms). Emilen toplam suyu belirlemek için numuneler, $105 \pm 5^{\circ} \mathrm{C}$ ' de 24 saat süresince kurutulmuş ve tartılmıştır (mk). Suya doymuş numunenin ağırlığ $(\mathrm{ms})$ ve 24 saat kurutulup oda sıcaklığında soğutulan numunenin ağırlığı (mk) kullanılarak ağırlıkça su emme oranı (\%), Eşitlik 1.'den hesaplanmıştır.

$$
\text { Su emme }(\%)=(m s-m k) / m k \times 100
$$

Numunelerde k1lcallık testi ASTM C 1585 [45] standardına uygun olarak, daha önce dört tarafı belli yüksekliğe kadar su geçirmez parafin ile kaplanmış 14 günlük 3 adet $5 \times 5 \times 5 \mathrm{~cm}$ boyutunda numune üzerinde, suyun sadece alttan tek yönlü alımının mümkün olacağ1 şekilde gerçekleştirilmiştir. Maruz kalan yüzey alanı başına kazanılan kümülatif kütlenin, zamanın (1., 4., 9., 16., 25., 36., 49., 64. dakika) kare köküne karşı grafiği çizilmiş ve ' $\mathrm{k}$ ' kılcallık katsayısının belirlenmesi için elde edilen verilerden geçirilen eğrinin eğimi dikkate alınmıştır.

\section{BULGULAR}

Üretilen 5 farklı karışımın taze özelliklerinin belirlenmesi amacıyla yayılma testi ve birim ağırlık tespiti gerçekleștirilmiştir. Karışımların yeterli işlenebilirliğe sahip olmaları açısından kullanılan akışkanlaştırıcı yüzdeleri değişiklik göstermiştir.

Yayılma testleri hem kontrol hem de lateks ikameli taze harçlar üzerinde gerçekleştirilmiş ve sonuçlar Şekil 3.'te sunulmuştur. Hedeflenen $20 \pm 5 \mathrm{~cm}$ yayılma çapı ile SBR lateksin oranlarının $\% 5, \% 10, \% 15$ ve $\% 20$ olması halinde yayılma çap değerleri sirasıyla 22,5, 23, 23 ve 25 $\mathrm{cm}$ olmuştur. \%20 SBR lateks katkılı harç karışımı akışkanlaştırıcı kullanılmamasına rağmen kontrol harcından \%25 daha fazla yayılma göstermiștir. K4 ve K5 karışımları yüksek SBR lateks kullanım oranlarına bağlı olarak yeterli yayılmayı sağladıklarından bu karışımlarda akışkanlaştırıcı malzeme kullanımı tercih edilmemiştir. Benzer sonuca, Baş [46] yürüttüğü çalışmada harcın içine koyulan lateks miktarı arttıkça harcın işlenebilir kıvamının oldukça arttığını gözlemleyerek ulaşmıştır. Yine, Shete ve Upase [47] bir SBR lateks çeşidi olan Rıpstar-148 ürününü kullanarak gerçekleştirdikleri çalışmada SBR latekslerin işlenebilirliğgi artırdığını göstermişlerdir. Sonuç olarak, 
çalışmada kullanılan SBR lateks tipinin de harçlarda işlenebilirliği arttırıcı etkiye sahip olduğu bilgisine ulaşılmıştır.

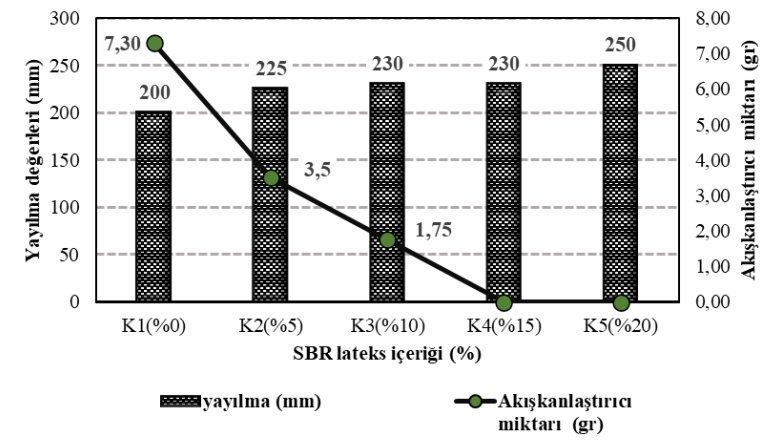

Şekil 3. Taze harçların yayılma değerleri

Kullanılan SBR lateks tipinin harçların taze ve sertleşmiş birim ağırlıkları üzerindeki etkisinin hangi oranlarda olduğu bilgilerine ulaşılması amacıyla birim ağırlık tayini gerçekleştirilmiştir. Taze ve sertleşmiş harç numunelerinin birim ağırlık değerleri Şekil 4.'de verilmiştir. Oldukça küçük farklılıklar ile de olsa tüm karışımlar için taze haldeki numunelerin birim ağırlık değerleri sertleşmiş numunelerden daha fazla olmuştur. Şekil 4 incelendiğinde SBR lateks katkı oranlarının üretilen karışımlar üzerindeki etkisi de görülmektedir. Kontrol numuneleri ile kıyaslandığında tüm durumlarda SBR lateks katkısı birim ağırlık değerlerini arttırmıştır. SBR lateks etkisi incelendiğinde ise hem taze hem de sertleşmiş durumlar için birim ağırlık değerleri $\% 10$ SBR lateks katkısına kadar artış gösterirken, \%15 ve $\% 20$ oranlarında gerçekleştirilen SBR lateks katkısı elde edilen birim ağırlık değerlerinde düşüşe neden olduğu görülmüştür. Bu durumun, hava muhtevasının azalması sebebiyle boşluğun yerini su ve lateksin doldurmasından kaynaklanmış olduğu söylenebilmektedir. Elde edilen sonuçlar literatürden elde edilen bilgiler ile uyum sağlamaktadır. Örneğin, Ceran [48] çalışmasında lateks ilavesinin kuru birim hacim ağırlığı arttırdığını fakat \%7 oranında lateks katılan harç numunesinde en büyük kuru birim hacim ağırlı̆̆ına ulaşıldığını ve diğer lateks ilaveli harç numunelerinin kuru birim hacim ağırlık değerlerinin birbirine yakın çıktığını gözlemlemiştir. Bir diğer çalışma da Baş [46] tarafindan gerçekleştirilmiştir. Lateks miktarı arttırıldıkça birim hacim ağırlı̆̆ının arttığını gözlemlemiştir ve $\% 23$ oranında lateks ilaveli harcın birim ağırlığı katkısız harçtan \%5,16 oranında daha büyük olarak ortaya çıkmıştır.

Yapılan çalışmada sertleşmiş numuneler arasında tespit edilen birim ağırlık sonuçları için en yüksek değer olan $2,4 \mathrm{gr} / \mathrm{cm}^{3}, \% 10$ SBR lateks ikamesi ile elde edilirken $2,15 \mathrm{gr} / \mathrm{cm}^{3}$ olan en düşük birim ağırlık değerine kontrol numunesi ile ulaşılmıştır. Sonuç olarak \%10 SBR lateks ikamesinin \%11,63'lük bir birim ağırlık artışına neden olduğu görülmüştür.

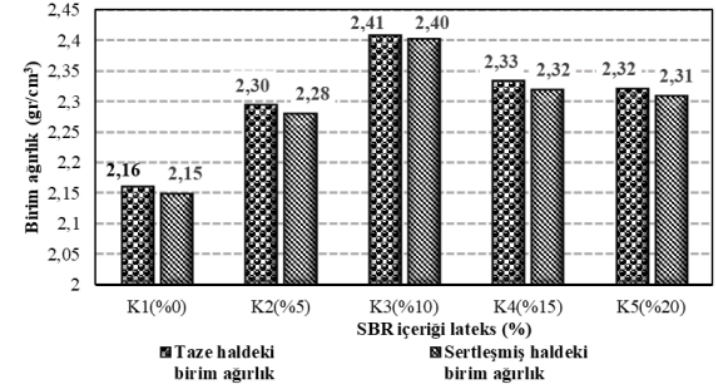

Şekil 4. Birim hacim ağırlık değerleri

Hazırlanan kontrol ve SBR lateks katkılı numuneler için mekanik özellikleri en iyi yansıtan basınç dayanım testi gerçekleştirilmiştir. Üretilen her karışımdan alınan 3 farklı numune için gerçekleştirilen eğilme testi sonucu elde edilen 6 numunenin ortalama basınç dayanım sonuçları Şekil 5.'te grafiksel olarak gösterilmiştir. Elde edilen sonuçlar incelendiğinde SBR lateks ikamesinin harç numunelerinin erken yaşta (14 gün) dayanım değerlerini düşürdüğü görülmektedir. Kontrol karışımı ile kıyaslandığında $\% 5, \% 10, \% 15$ ve $\% 20$ oranlarında SBR lateks ikamesi basınç dayanım değerlerinde surasiyla $\% 17,48, \% 31,63, \% 42,18$ ve $\% 55$ oranlarında düşüşe neden olmuştur. Shirshova vd. [33] çimento kütlesine göre \%14 SBR içeren çimento bulamacinı değerlendirmişlerdir: SBR polimer lateks kullanımı nedeniyle sürekli bir polimer ağı oluştuğunu ve bu durumun çimento hamurunun basınç dayanımı üzerinde olumsuz etki gösterirken gerilme-göçme oranını arttırdığını bildirmişlerdir. Baş [46] tarafından yürütülen çalışmada 28 günlük harç numunelerinde lateks ilavesinin katkısız örneklere göre basınç dayanımı değerlerindeki etkisi incelenmiştir. Basınç dayanımı değerleri için, $\% 4,6$ lateks ilaveli numunelerde $\% 28,5$, $\% 11$ lateks ilaveli numunelerde \%26,30, \%23 lateks ilaveli numunelerde ise $\% 19,8$ oranında düşüş gözlenmiş̧ir. Shete ve Upase [47] SBR lateks çeşidi olan Rıpstar-148 kullanarak gerçekleştirdikleri çalışmada SBR lateksin 7 günlük basınç dayanımını olumsuz etkilediğini göstermişlerdir. Yao ve Ge [49] lateks katkısının tüm hazırlanan numunelerin 28 günlük basınç dayanımını azalttığını belirlemişlerdir. SBR lateks ilavesinin basınç dayanımını düşürmesinin nedenini, polimer filmin oluşması, polimer yapısının gelişmesi ve Portland çimento matrisinin oluşumu için yeterli zamanın olması gerektiği bilgisi ile açıklamak mümkündür.

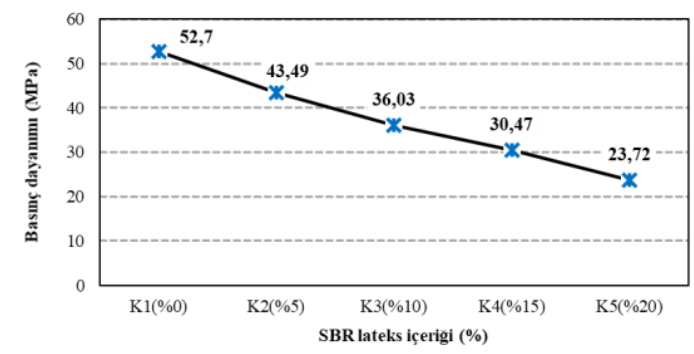

Şekil 5. Basınç dayanımı değerleri

Üretilen numunelerin çekme etkisi altındaki davranışının incelenmesi amacıyla eğilmede çekme deneyi gerçekleştirilmiştir. Eğilme dayanım testinin sonuçları Şekil 6.'da grafiksel olarak gösterilmiştir. Kontrol 
karışımı için 5,95 $\mathrm{MPa}$ olarak elde edilen eğilmede çekme dayanım değeri SBR lateks ikamesi sonucunda 5,63 $\mathrm{MPa}$ ile 6,12 $\mathrm{MPa}$ arasında değişiklik göstermiştir. Eğilme dayanımı, \%0 SBR-kontrol numunelerine göre tüm karışımlarda azalmasına rağmen \%10 SBR ikamesinde yaklașık \%3 oranında artış göstermiștir. Ayrıca, erken yaşta eğilme dayanımı değerlerinde $\% 5$ SBR serisi için \%5,5, \%15 SBR serisi için \%9,4, ve \%20 SBR serisi için \%23,7 oranında azalma olduğu belirlenmiştir. Eğilme dayanımının kullanılan oranlara göre farklılık göstermesi lateksin harç bünyesindeki etki mekanizması ile ilişkilendirilebilir. \%10 oranında lateks ikamesi polimer ağın yapısını ve oluşan lif tabakanın etki alanını olumlu yönde değiştirerek boşluk dağılımını değiştirmiştir. Literatürde bu konuda farklı oranlar için elde edilen benzer sonuçlar mevcuttur. Baş [46], \%11 lateks ilavesinin 28 günlük harcın eğilme dayanımında katkısız harca göre \%3,6 oranında artışa, \%23 oranında lateks ilavesinin eğilme dayanımında $\% 11$ oranında düşüşe sebep olduğunu bildirmiştir. Ahmed ve ark. [50] ise $\% 8$ oranında lateks katkısının numunelerin eğilme dayanımında \%11 oranında artış sağladığını fakat bu değerden sonra eğilme dayanımının düştüğünü belirtmişlerdir. Sonuç olarak üretilen SBR lateks katkılı karışımlar arasında en yüksek eğilmede çekme dayanım değeri olan 6,12 $\mathrm{MPa}^{\prime} 1$ veren seri $\mathrm{K} 3$ (\%10 $\mathrm{SBR}$ ) olmuştur. En düşük eğilmede çekme dayanım değerine ise K5 (\%20 SBR) serisi ile ulaşılmıştır.

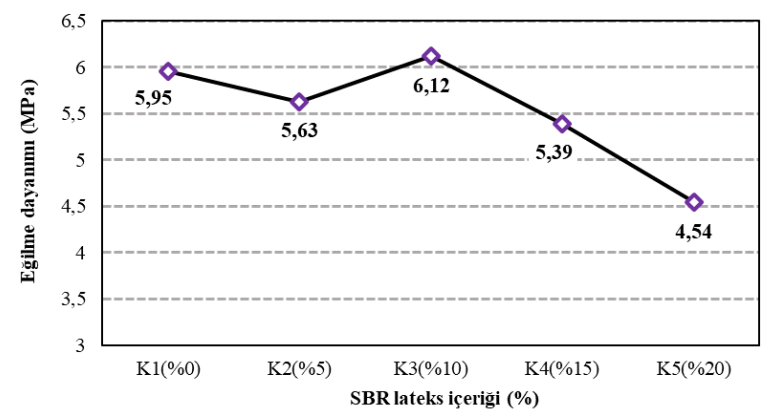

Şekil 6. Elde edilen harç numunelerinin eğilme dayanımı değerleri

Lateks karışımlı harçların su emme değerleri, kontrol karışımlarının değerleri ile birlikte Şekil 7.'de gösterilmektedir. Kontrol karışımı ile kıyaslandığında SBR lateks kullanılan karışımların su emme değerlerinde düşüş gözlenmiştir. $\mathrm{Bu}$ azalmanın polimer film oluşumundan kaynaklandığını söylemek mümkündür. Ceran [48], çalıșmasında lateks ilavesinin su emme yüzdesinde azalmaya neden olduğu sonucuna varmıştır. Shete ve Upase [47] Rıpstar-148 çeşidi bir SBR lateks kullanarak katkısız numuneye göre SBR lateks katkılı numunelerin su emme yüzdelerinde bir azalmanın meydana geldiğini göstermişlerdir. $\mathrm{Su}$ emme değerlerinde görülen bu düşüşler SBR lateks artış oranlarında farklılık göstermiştir. $\% 15$ ve $\% 20$ oranında SBR lateks ilavesi ile oluşan polimer ağlar düzgün homojen bir dağılım gösteremediğinden $\% 5$ ve $\% 10$ SBR lateks ikamesine göre boşluk yapısını iyileştirmede daha az etkili olmuş ve su emme değerlerinde artışa neden olmuștur. Kontrol karıșımı için \%6,82 olan su emme değeri $\% 5, \% 10, \% 15$ ve $\% 20$ oranlarında SBR lateks ilaveleri ile sirasiyla $\% 15,98, \% 16,13, \% 2,05$ ve
\%9,38 oranlarında azalıș göstermiștir. K2 (\%5 SBR) ve K3 (\%10 SBR) serileri için elde edilen su emme sonuçları birbirine oldukça yakın değerler olmuştur. Maksimum su emme oranına $\% 15$ oranında lateks ikamesi ile ulaşılırken, minimum su emme değeri \%10 SBR lateks içeren karışım ile elde edilmiştir. Ulaşılan bu en yüksek ve en düşük su emme değerleri sırasıyla $\% 5,72$ ve $\% 6,68$ olarak elde edilmiştir. Lateksli numuneler kontrol numuneleri ile kiyaslandığında, kontrol numunesine en yakın su emme yüzdelerine \%15 lateks katkılı numuneler ile ulaşıldığı görülmüştür.

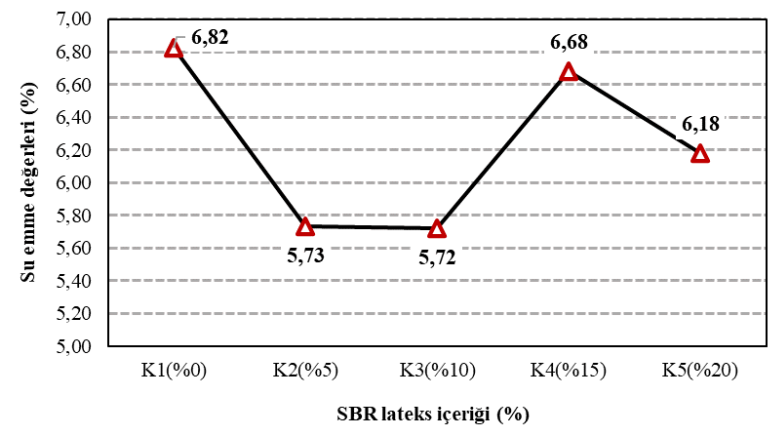

Sekil 7. Harç numunelerinin su emme değerleri

Hazırlanan karışımların bünyesinde bulunan boşluk yapıları ve birbirleriyle olan bağlantılarının incelenmesi amacıyla kılcal su emme deneyi gerçekleştirilmiştir. Lateks katkılı harçların kılcallık katsayısı değerleri, kontrol karışım değeri ile birlikte Şekil 8.'de gösterilmektedir. Kontrol numuneleri ile kıyaslandığında, tüm SBR lateks içeren harç karışımlarının $(\% 5, \% 10, \% 15, \% 20$ SBR) kılcallık katsayılarında azalma görülmüştür. Sonuçlar incelendiğinde $\% 20$ oranında lateks ikamesinin kılcallık katsayısında diğer oranlara göre düşük bir oranda artırıcı etkisinin olduğu görülmektedir. SBR lateksin oluşum mekanizması dikkate alındığında bu durumun oluşmasında meydana gelen monolitik ağın bağlantılı boşluklardaki dağılımı belirleyici olma. Kontrol karışımına ait harç numunesi için $0,1 \mathrm{gr} /\left(\mathrm{mm}^{2} \sqrt{\mathrm{dak}}\right)$ olarak elde edilen k1lcallık katsayıs1 \%5, \%10, \%15 ve $\% 20$ oranlarında lateks kullanımı ile sırasıyla 0,06, 0,04, 0,009 ve $0,013 \mathrm{gr} /\left(\mathrm{mm}^{2} \sqrt{\text { dak }}\right)$ değerlerine düşmüştür. Ancak \%15 ve \%20 SBR katkılı numunelerin su emme yüzdelerinin yüksek değerlerde elde edilmesi ile birlikte kılcallık değerlerinin düşük çıkması numunelerin bünyesinde bulunan boşlukların bağlantı yapısından kaynaklı olabilmektedir. Ceran [48] tarafından yapılan çalışmaya göre katkısız harç numunesinin 7 . gündeki kılcallık katsayısı değeri sonraki yaşlarda büyük bir azalma göstermistir. Lateks katkılı harçların kılcallık katsayısı katkısız harçlara göre oldukça düşük iken, bu fark 7. günde yaklasık 5 kat olup sonraki yaşlarda gittikçe düşmüştür. 


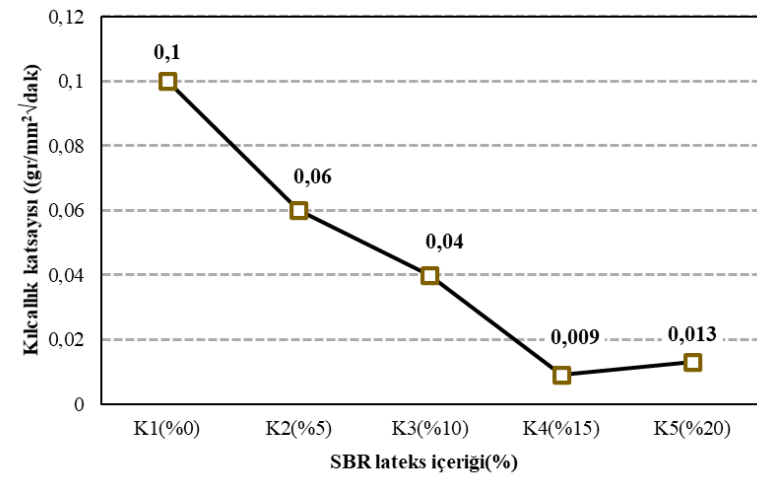

Şekil 8. Harç numunelerinin kılcallık katsayısı değerleri

Şekil 9.'da elde edilen basınç dayanım sonuçları ile kılcallık katsayıları arasındaki ilişkiyi veren denkleme ve $\mathrm{R}^{2}$ değerine yer verilmiştir. Kılcallık katsayısı değerleri 0,013 ile $0,1 \mathrm{gr} /\left(\mathrm{mm}^{2} \sqrt{\text { dak}}\right)$ arasında değişirken, basınç dayanım sonuçları 23,72 ile $54,7 \mathrm{MPa}$ arasında değişmiştir. Kılcallık katsayısı ve basınç dayanımı sonuçları arasında $0,97 \mathrm{R}^{2}$ değeri ile oldukça iyi bir ilișki elde edilmiştir. Numunelerin bünyesinde bulunan bağlantılı boşluk yapılarının dayanım sonuçlarını doğru orantılı olarak etkilediği görülmüştür.

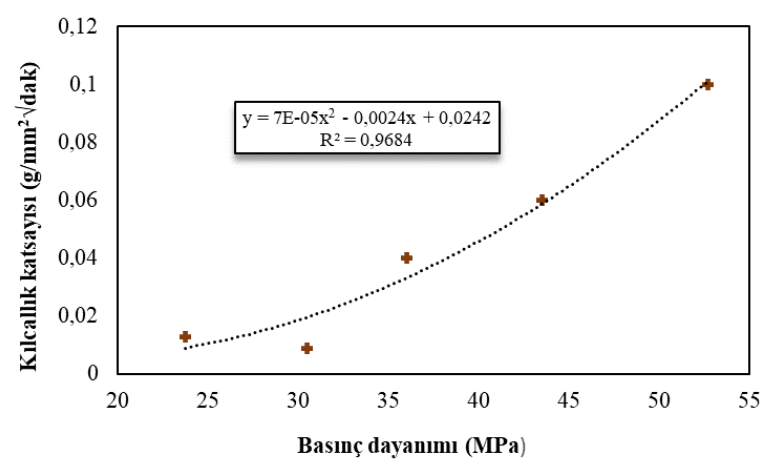

Şekil 9. Basınç dayanımı ile kılcallık katsayısı arasındaki ilişki

\section{SONUÇ}

Yürütülen çalışma kapsamında SBR lateks kullanımının harç numunelerinin taze ve sertleşmiş özellikleri üzerindeki etkisi incelenmiştir. Taze harç karışımları için yayılma ve birim ağırlık sonuçları elde edilirken, sertleşmiş durumdaki numuneler üzerinde ise birim ağılık, basınç dayanımı, eğilme dayanımı, su emme ve kılcal su emme deneyleri gerçekleştirilmiş̧ir. $\mathrm{Bu}$ kapsamda hazırlanan 5 farklı karışım için ulaşılan deney sonuçları irdelenerek kullanılan SBR lateks tipinin harç numuneler üzerindeki etkisi incelenerek, uygulanabilirliği belirlenmiştir. Elde edilen sonuçlar aşağıda sıralanmıştır:

4 farklı SBR lateks oranları (\%5, \%10, \%15, \%20) kullanılarak üretilen harçların yayılma çaplarının belirlenmesi sonucunda elde edilen veriler lateks oranlarındaki artışın harçların işlenebilirliğini arttırdığını göstermiştir.

Sertleşmiş numuneler üzerinde yapılan çalışmalar kapsamında gerçekleştirilen eğilmede çekme dayanım test sonuçlarına göre erken yaştaki eğilme dayanım değerleri lateks miktarının artmasıyla azalırken, eğilme dayanım değerlerinin \%10 lateks katkılı numunelerde $\% 3$ civarında arttığı gözlenmiştir.

Hazırlanan harç numuneleri için erken yaştaki basınç dayanımı değerleri lateks oranı arttıkça azalmıştır. Bu durumun polimer yapısının ve çimento hidratasyonunun oluşum ve gelişim aşamalarından kaynaklandığını söylemek mümkündür.

Lateks katkı1ı numunelerin su emme yüzdeleri kontrol numuneleri ile karşılaştırıldığında daha düşük olarak elde edilmiştir. Bu azalmanın polimer film oluşumundan kaynaklandığını söylemek mümkündür. Maksimum su emme oranına \%15 oranında lateks ikamesi ile ulaş1lırken, minimum su emme değeri \%10 SBR lateks içeren karışım ile elde edilmiştir.

Lateks miktarının artmasıyla numunelerin birim hacim ağırlıklarının arttı̆̆g gözlenmiştir. Birim hacim ağılılığın artmış olmasının, hava muhtevasının azalması sebebiyle oluşan boşlukların yerini su ve lateksin doldurmasından kaynaklı olabileceği düşünülmektedir.

Kontrol numuneleri ile kıyaslandığında lateksli harç numunelerinin kılcallı katsayısının azaldığ görülmüştür. $\% 15$ ve $\% 20$ SBR katkılı numunelerin su emme yüzdeleri yüksek değerde çıktığı halde kılcallık değerlerinin düşük çıkmasının numune içindeki boşluk yapısı ve bağlantısı ile ilgili olduğu söylenebilir.

Elde edilen basınç dayanım sonuçları ile kılcallık katsayıları arasında $0.87 \mathrm{R}^{2}$ değerine sahip doğru orantılı bir iliş̧kinin olduğu belirlenmiştir.

Kullanılan SBR lateks tipine ve oranlarına bağlı olarak yapılan deneylerden elde edilen sonuçlar değişkenlik gösterebilmektedir. Yapılacak çalışmalarda bu durum dikkate alınarak farklı oran ve tiplerde SBR lateks kullanımının harçların taze ve sertleşmiş özellikleri üzerindeki etkisi incelenebilir. Ayrıca farklı kürleme şartlarına bağlı olarak durabilite özelliklerinin belirlenmesi de hedeflenebilir.

\section{KAYNAKLAR}

[1] Palson P, Vidivellı B. Mechanical properties of latex modified concrete with silica fume. International Journal of Civil Engineering and Technology. 2017;8(9):701-710.

[2] Kardon, Joshua B. Polymer-modified concrete. Journal of Materials in Civil Engineering. 1997;9(2):85-92.

[3] Stampino PG, Zampori L, Dotelli G, Meloni P, Sora IN, Pelosato R. Use of admixtures in organiccontaminated cement-clay pastes. Journal of Hazardous Materials. 2009;161(2-3):862-870.

[4] Aggarwal LK., Thapliyal PC, Karade SR. Properties of polymer-modified mortars using epoxy and acrylic emulsions. Construction and Building Materials. 2017;21(2):379-383.

[5] Eren F, Gödek E, Keskinateş M, Tosun-Felekoğlu K, Felekoğlu B. Effects of latex modification on 
fresh state consistency, short term strength and long term transport properties of cement mortars. Construction and Building Materials. 2017;133:226-233.

[6] Rozenbaum O, Pellenq RM, Van Damme H. An experimental and mesoscopic lattice simulation study of styrene-butadiene latex-cement composites properties. Materials And Structures. 2005;38(4):467-478.

[7] Lavelle JA. Acrylic latex-modified Portland cement. Materials Journal. 1988;85(1):41-48.

[8] Kim HK, Lee MH. Generalized Eichler-Shimura isomorphisms for compact locally symmetric spaces. Osaka Journal of Mathematics. 1988;35(2):407-415.

[9] Dayo AA, Kumar A, Raja A, Bheel N, Shaikh ZH. Use of sugarcane bagasse ash as a fine aggregate in cement concrete. Engineering Science and Technology International Research Journal. 2019;3(3):8-11.

[10] Wagner HB. Polymer-modified hydraulic cements. Industrial \& Engineering Chemistry Product Research and Development. 1965:4(3):191-196.

[11]Radhakrishnan R, SyamPrakash V, Thampan CK, Varma P. Performance of styrene butadiene rubber as a concrete repair material in tropical climate. International Journal of Advancements in Research \& Technology. 2012;1(6):118-122.

[12]Afridi MUK, Ohama Y, Iqbal MZ, Demura K. Behaviour of $\mathrm{Ca}(\mathrm{OH}) 2$ in polymer modified mortars. International Journal of Cement Composites and Lightweight Concrete. 1989;11(4):235-244.

[13] Lho BC, Joo, MK, Choi KH, Choi JY. Effects of polymer-binder ratio and slag content on strength properties of autoclaved polymer-modified concrete. KSCE Journal of Civil Engineering. 2012;16(5):803-808.

[14]Hwang EH, KoYS, Jeon JK. Effect of polymer cement modifiers on mechanical and physical properties of polymer-modified mortar using recycled artificial marble waste fine aggregate. Journal of Industrial and Engineering Chemistry. 2008;14(2):265-271.

[15]Yao SY, Ge Y. Effect of styrene butadiene rubber latex on mortar and concrete properties. Advanced Engineering Forum. 2012;5:283-288.

[16]Ohama Y. Principle of latex modification and some typical properties of latex-modified mortars and concretes adhesion; binders (materials); bond (paste to aggregate); carbonation; chlorides; curing; diffusion. Materials Journal. 1987;84(6):511-518.

[17]Baghini MS, Ismail A, Karim MR, Shokri F, Firoozi AA. Effect of styrene-butadiene copolymer latex on properties and durability of road base stabilized with Portland cement additive. Construction and Building Materials. 2014;68:740-749.

[18]Doğan M, Bideci A. Effect of styrene butadiene copolymer (SBR) admixture on high strength concrete. Construction and Building Materials. 2016;112:378-385.

[19]Kim KK, Yeon J, Hee Lee J, Yeon KS. Feasibility study of SBR-modified cementitious mixtures for use as 3D additive construction materials. Polymers. 2019;11(8):1321.

[20] Kardon JB. Polymer-modified concrete. Journal of Materials in Civil Engineering. 1997;9(2):85-92.

[21] Sakai E, Sugita J. Composite Mechanism of Polymer Modified Cement. Cement and Concrete Research. 1995;25(1):127-135.

[22] Ollitrault-Fichet R, Gauthier C, Clamen G, Boch P. Microstructural Aspects in a Polymer-Modified Cement. Cement and Concrete Research. 1998;28(12):1687-1693.

[23] Kim MO. Influence of Polymer Types on the Mechanical Properties of Polymer-Modified Cement Mortars. Applied Sciences. 2020;10(3):1061.

[24] Ohama Y, Nishimura T, Miyaka T, Kan S. Proposed Mix Proportioning of Polymer-Modified Concrete. In: proc. of the 3rd Int. Cong, on Polymers in Concrete. Koriyama;Japan; 1982. p. 178-192.

[25] Rossignolo JA. Effect of silica fume and SBR latex on the pasteaggregate interfacial transition zone. Materials Research. 2007;10(1):83-86.

[26] Benali Y, Ghomari F. Mechanical behavior and durability of latex modified mortars. Journal of Building Materials and Structures. 2018;5(1):110126.

[27] Idrees M, Nazar R. Effect of SBR on physical and mechanical properties of concrete. 10 th International Concrete Congress. Bursa, 2019. p. 9.

[28] Rossignolo JA, Agnesin MV. Durability of polymer-modified lightweight aggregate concrete. Cement and Concrete Composites. 2004;26(4):375380.

[29] Shafieyzadeh M. Prediction of compressive strength of concretes containing silica fume and styrene-butadiene rubber (SBR) with a mathematical model. International Journal of Concrete Structures and Materials. 2013;7(4):295301.

[30] Essa MS, Abdul-Amir AM, Hassan NF. Effect of Adding (SBR) on Concrete Properties and Bond Between Old and New Concrete. Kufa journal of Engineering. 2012;4(1):81-95.

[31] Soni K, Joshi YP. Performance analysis of styrene butadiene rubber-latex on cement concrete mixes. Journal of Engineering Research and Applications. 2014;3(1):838-44.

[32] Bideci A, Doğan M, Çomak B, Bideci ÖS, Besli E. Stiren-Bütadien Kopolimer Katkısının Çimento Harçlarına Etkisi. Düzce Üniversitesi Bilim ve Teknoloji Dergisi. 2016;4(1).

[33] Shirshova N, Menner A, Funkhouser GP, Bismarck A. Polymerised high internal phase emulsion cement hybrids: Macroporous polymer scaffolds for setting cements. Cement and Concrete Research. 2011;41(4):443-450.

[34] Schulze J. Influence of Water-Cement Ratio and Cement Content on the Properties of PolymerModified Mortars. Cement and Concrete Research. 1999;29(6):909-915.

[35] Wu KR, Zhang D, Song JM. Properties of polymermodified cement mortar using pre-enveloping 
method. Cement and Concrete Research. 2002;32(3):425-429.

[36] Issa MA, Alhassan MA, Shabila H. Highperformance plain and fibrous latex-modified and microsilica concrete overlays. Journal of Materials in Civil Engineering. 2008;20(12):742-753.

[37] Shaukat AJ, Feng H, Khitab A, Jan A. Effect of Admixtures on Mechanical Properties of Cementitious Mortar. Civil Engineering Journal. 2020;6(11):2175-2187.

[38] Singh SB, Pankaj Munjal, and Nikesh Thammishetti. Role of Water/cement Ratio on Strength Development of Cement Mortar. Journal of Building Engineering. 2015;4:94-100.

[39] Tchetgnia Ngassam IL, Marceau S, Chaussadent T. Durability of polymer modified repair mortars on concrete structures. In Advanced Materials Research. 2013;687:397-402.

[40] Wang M, Wang R, Yao H, Farhan S, Zheng S, Wang Z, et al. Research on the mechanism of polymer latex modified cement. Construction and Building Materials. 2016;111:710-718.

[41] American Society for Testing and Materials, ASTM C1437-01: Standard test method for flow of hydraulic cement mortars, Annual Book of ASTM Standards. Philadelphia:2005; p. 611-612.

[42] ASTM, C. C138-Standard Test Method for Unit Weight. Yield, and Air Content (Gravimetric) of Concrete. 2001.

[43] ASTM, C. Standard test method for flexural strength of concrete (using simple beam with thirdpoint loading). In American society for testing and materials. 2010;100:p. 19428-2959.

[44] Standard, A. S. T. M. C642. Standard Test Method for Density, Absorption, and Voids in Hardened Concrete. ASTM International, West Conshohocken, PA, 2013.

[45] ASTM, C. (2013). 1585. Standard Test Method for Measurement of Rate of Absorption of Water by Hydraulic-", ASTM Int, 4-9.

[46] Baş B. Lateks katkılı sıva harçlarının özelikleri. Yüksek Lisans Tezi, İstanbul Teknik Üniversitesi, Fen Bilimleri Enstitüsü; 2009.

[47] Shete GN, Upase KS. Evaluation of compressive strength and water absorption of styrene butadiene rubber (SBR) latex modified concrete. International Journal of Modern Engineering Research (IJMER). 2014;4(10):40-44.

[48] Ceran A. Polimer esaslı lateks katkının çimento harç özelikleri üzerindeki etkisinin incelenmesi, Yüksek Lisans Tezi, Mimar Sinan Güzel Sanatlar Üniversitesi Fen Bilimleri Enstitüsü; 2009.

[49] Yao SY, Ge Y. Effect of styrene butadiene rubber latex on mortar and concrete properties. In Advanced Engineering Forum. 2012;5:283-288.

[50] Ali AS, Jawad HS, Majeed IS. Improvement the Properties of Cement Mortar by Using Styrene Butadiene Rubber Polymer. Journal of Engineering and Development. 2012;16(3):1813-7 